\title{
LUTA ANTIRRACISTA NA EDUCAÇÃO INFANTIL EM TEMPOS DE PANDEMIA: 0 QUE AS TÁTICAS DOCENTES REVELAM?
}

\author{
ANTI-RACIST FIGHT IN CHILDHOOD EDUCATION IN PANDEMIC TIMES: WHAT DO TEACHING \\ TACTICS REVEAL? \\ LUCHA ANTIRACISTA EN LA EDUCACIÓN INFANTIL EN TIEMPOS DE PANDEMIA: ¿QUÉ REVELAN LAS \\ TÁCTICAS DE ENSEÑANZA?
}

\author{
Daise dos Santos Pereira ${ }^{1}$ \\ Marcia Guerra Pereira ${ }^{2}$ \\ Alana Alves Pereira ${ }^{3}$ \\ Maria Cecília Ribeiro da Paixão ${ }^{4}$
}

\section{RESUMO}

A opção pela continuidade do ano letivo de 2020, na forma remota emergencial no Estado do Rio de Janeiro, resultou de deliberação político-administrativa exclusiva das instâncias de governo, cuja aplicação não foi acompanhada de um debate amplo e participativo na sociedade e, em particular, entre os profissionais de ensino, responsáveis pelos discentes e comunidade acadêmica. O objetivo deste artigo é apresentar táticas usadas por professores da educação infantil para uma educação antirracista, em meio às inadequações das instituições, realidades locais e as limitações de atendimento mínimo dos objetivos previstos na legislação brasileira relativos a cada nível de ensino. Tais astúcias dos praticantes do cotidiano são apontadas como decisivas, no sentido de evitar que a acentuada desigualdade social no interior da sociedade seja agravada pelas precárias condições de inclusão digital presentes nos lares brasileiros. Como demonstração do resultado da pesquisa, alicerçada em narrativas de docentes atuantes na educação infantil do município de Magé e interpretadas por meio da combinação dos conceitos de Boaventura de Souza Santos, Michel de Certeau e de Paulo Freire, são apresentadas três experiências do emprego de táticas que subvertem às funções atribuídas ao ensino remoto pelos gestores educacionais.

PALAVRAS-CHAVE: Ensino Remoto. Educação Antirracista. Narrativas Docentes. Produção Audiovisual. Educação Infantil.

Submetido em: 21/01/2021 - Aceito em: 18/02/2021 - Publicado em: 12/072021

1 Pedagoga, doutoranda no Programa de Pós-Graduação da Faculdade de Educação da Pontifícia Universidade Católica do Rio de Janeiro (PUC-Rio), Professora da Educação Básica nos municípios de Magé e Petrópolis.

${ }^{2}$ Doutora pelo Programa de Pós-graduação em Educação, História e Sociedade da Pontifícia Universidade Católica de São Paulo (PUCSP). Professora do Instituto Federal do Rio de Janeiro (IFRJ)/Especialização em Histórias e Culturas da África e dos Afro-Brasileiros.

${ }^{3}$ Geografa pela Universidade do Estado do Rio de Janeiro (UERJ). Especializada Alfabetização das Crianças das Classes Populares pela UFF. Professora da Educação Básica no município de Magé.

${ }^{4}$ Pedagoga pela Universidade do Estado do Rio de Janeiro (UERJ). Pós-graduanda em Histórias e Culturas da África e dos Afro-Brasileiros (IFRJ). Professora da Educação Básica no município de Magé. 


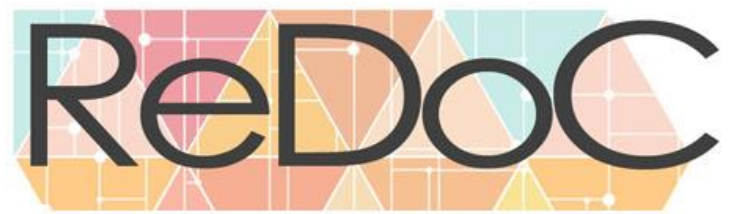

\title{
Revista Docência e Cibercultura
}

\begin{abstract}
The option for the continuity of the 2020 school year, in the remote emergency form in the State of Rio de Janeiro, resulted from a political-administrative deliberation exclusive to the government instances, whose application was not accompanied by a wide and participative debate in society and, in particular, among the teaching professionals, responsible for the students and the academic community. The objective of this article is to present tactics used by early childhood education teachers for an anti-racist education, amid the inadequacies of the institutions, local realities, and the limitations of minimum attendance of the objectives foreseen in the Brazilian legislation regarding each level of education. Such cunning by day-to-day practitioners is pointed out as decisive, in order to avoid that the accentuated social inequality within society is aggravated by the precarious conditions of digital inclusion present in Brazilian homes. As a demonstration of the results of the research, based on the narratives of teachers working in early childhood education in the municipality of Magé and interpreted by combining the concepts of Boaventura de Souza Santos, Michel de Certeau and Paulo Freire, three experiences are presented of the use of tactics that subvert the functions attributed to remote teaching by educational managers
\end{abstract}

KEYWORDS: Remote Teaching. Antirracist Education. Teaching Narratives. Audiovisual Production. Early Childhood Education.

\section{RESUMEN}

La opción por la continuidad del año escolar 2020, por medio remoto emergencial en el Estado de Río de Janeiro, resultó de una deliberación político-administrativa exclusiva de los órganos de gobierno, cuya aplicación no fue acompañada de un debate amplio y participativo en la sociedad y, en particular, entre los profesionales de la enseñanza, los responsables de los estudiantes y la comunidad académica. El objetivo de este artículo es presentar las tácticas utilizadas por los maestos de educación infantil para una educación antirracista, en medio de las insuficiencias de las instituciones, las realidades locales y las limitaciones de la asistencia mínima a los objetivos previstos en la legislación brasileña relacionada con cada nivel de educación. Esta astucia de los profesionales del día a día se señala como decisiva, para evitar que la marcada desigualdad social dentro de la sociedad se agrave por las precarias condiciones de inclusión digital presentes en los hogares brasileños. Como demostración de los resultados de la investigación, a partir de los relatos de los maestros que trabajan en la educación infantil en el municipio de Magé/RJ e interpretados combinando los conceptos de Boaventura de Souza Santos, Michel de Certeau y Paulo Freire, se presentan tres experiencias de uso de tácticas que subvierten las funciones atribuidas a la enseñanza a distancia por los gestores educativos.

PALABRAS CLAVE: Enseñanza a Distancia. Educación Antirracista. Narrativas de Enseñanza. Producción Audiovisual. Educación Infantil.

\section{INTRODUÇÃO}

Somente quando os oprimidos descobrem, nitidamente, o opressor, e se engajam na luta organizada por sua libertação, começam a crer em si mesmos, superando, assim, sua "convivência" com o regime opressor. Se esta descoberta não pode ser feita em nível puramente intelectual, mas da ação, o que nos parece fundamental é que esta não se cinja a mero ativismo, mas esteja associada a sério empenho de reflexão, para que seja práxis.

(FREIRE, 1987. p.52) 


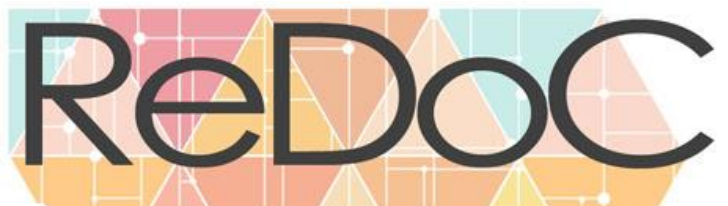

\section{Revista Docência e Cibercultura}

Março de 2020 e, como um rastilho de pólvora, o vírus da COVID-19 se espalha pelo mundo. Nós, nem os governos, tínhamos clareza do que estávamos vivendo. Sabíamos que era novo e letal. A saída foi parar as atividades, todas, inclusive as escolas. Nada parecido acontecera antes. Crianças e jovens de todo mundo mantidos em suas casas, escolas fechadas, ameaçados pela morte. Por quanto tempo? Não sabíamos.

Passadas as primeiras semanas, a insegurança ainda reinava. Em relação ao sistema escolar, a interrupção das atividades é questionada de diferentes maneiras: há os que questionam a quebra do hábito de estudar, os que se desesperam por se verem incapazes de entreter crianças ao longo de dias inteiros, os que pensam em como cumprir calendários e burocracias as mais diversas, os que sentem falta da socialização, os que anseiam pelo contato direto, por olhar nos olhos, por estar simplesmente no ambiente escolar. Não havia um conhecimento acumulado sobre o que fazer: aulas pela TV? Apostilas pelo correio? Rádio em frequência modulada? Suspenção do ano letivo? Neste momento, quando não tínhamos uma referência de como proceder, deixamos passar a oportunidade de um diálogo fraterno sobre o lugar da escola e do seu papel no mundo contemporâneo. Uma instituição que, não importa onde estejamos, em Magé ou em Buenos Aires, em Kinshasa ou Nairobi, está longe de satisfazer a sociedade em que se insere. Fomos solicitados a retomar nossas atividades remotamente.

Frente a esse desafio, que rompia a premissa do contato direto entre os envolvidos no ato de educar, que nos deixava distantes do corpo que expressa tantas coisas, do carinho que ajuda a compreensão, do olhar que questiona - em particular em se tratando da educação infantil, passamos a realizar atividades educativas à distância. Para um conjunto de professores mundo a fora foi mais uma vez colocado o desafio de reinventar o seu fazer pedagógico. Em geral, somos os mesmos que já o fazíamos na escola presencial. Pois sabemos que é possível abrir espaços no interior de instituições que são feitas para reproduzir o que não satisfaz. Que é possível se contrapor ao que é desprovido de sentido. Neste particular, o exemplo dos avanços alcançados no combate ao racismo nos serve de horizonte e cartillha. ${ }^{5}$ Presencialmente, ou a distância, temos a compreensão do nosso papel na superação das desigualdades que só se agudizam ao longo desses tempos pandêmicos. Compreensão essa, que talvez precisemos reafirmar a cada manhã e alimentá-la com doses de razão aquecida, ou seja, por um Corazonar, ${ }^{6}$ que segundo Santos (2019) possui múltiplas dimensões, não obstante, destacaremos algumas:

Corazonar significa experienciar o infortúnio ou o sofrimento injusto dos outros como se fossem próprios e estar disponível para se aliar à luta contra essa injustiça, ao ponto mesmo de correr riscos. Significa acabar com a passividade e fortalecer o

\footnotetext{
${ }^{5}$ Para a percepção do que estamos chamando de avanços no combate ao racismo no interior das escolas sugerimos a leitura do texto O Movimento Negro Educador, escrito por Nilma Lino Gomes.

${ }^{6}$ Segundo Boaventura de Sousa Santos, o conceito Corazonar surge das lutas dos povos indígenas e afrodescendentes da América Latina.
} 
inconformismo perante a injustiça. Corazonar nunca significa que as emoções deem origem a uma falta de controle. Pelo contrário, as emoções são a energia vital que impele as boas-razões-para-agir a passarem à ação ponderada (...). Corazonar é uma forma amplificada de ser -com, pois faz crescer a reciprocidade e a comunhão (...) (2019, p. 154)

Talvez, uma das coisas mais essenciais nesse tempo, seja fortalecer o inconformismo perante às injustiças que acomentem à tantos que estão à margem da sociedade, e nessa direção, ofertar sensibilidade, solidariedade, direito à experimentações, respeito às singularidades. Tantas outras contribuições têm sido pensadas para/com àqueles que fazem o nosso ofício mais bonito e honesto: nossos alunos, que oriundos das classes populares, seguem massacrados com os efeitos de uma crise humanitária.

São muitas as durezas e truculências desse tempo que nós professores corazonados buscamos atenuar. - Como? Perguntariam céticos e egoístas. Diríamos que a criatividade e uma determinada determinação ${ }^{7}$ podem ser estruturantes para motivar a luta contra o que nos oprime e violenta, mesmo que as chances de vitória sejam poucas. Em síntese, esses caminhos são traduzidos por Santos (2019) como "razão suficientemente corazonada”.

Boaventura de Sousa Santos (2018) nos diz que certos conceitos funcionam como raízes que permitem aos seres humanos alçar vôo. A palavra tática, presente no título deste texto, tem disso, nos habilita a voar. Segundo o dicionário Aurélio, o termo "tática" significa a arte de dispor e manobrar as tropas no campo de batalha para conseguir o máximo de eficácia durante um combate. $\mathrm{Ou}$, ainda, designa a parte da arte da guerra que trata de como proceder durante um combate ou uma batalha.

Epistemologicamente, tática é uma categoria utilizada pelo historiador francês Michel de Certeau e que lançamos mão para potencializar nossas reflexões. Em A Invenção do Cotidiano: as artes de fazer, o autor a emprega em contraponto a de estratégia, importando-as do contexto militar, do qual são originárias. Os detentores do poder podem fazer ações totalizadoras, de amplo espectro. Quanto as pessoas comuns, como nós, professoras, agimos nas fímbrias, pontualmente. Nosso campo de ação é a tática. Nas palavras do Certeau, o conceito de estratégia é explicado como:

Chamo de estratégia o cálculo (ou a manipulação) das relações de forças que se torna possível a partir do momento em que um sujeito de querer e poder (uma empresa, um exército, uma cidade, uma instituição científica) pode ser isolado. A estratégia postula um lugar suscetível de ser circunscrito como algo próprio e ser a base de onde se podem gerir as relações com uma exterioridade de alvos ou ameaças (os clientes ou

\footnotetext{
${ }^{7}$ Alusão às palavras de Teresa D’Avila, pensadora, escritora e mística transgressora do período da Contrarreforma na Espanha.
} 
os concorrentes, os inimigos, o campo em torno da cidade, os objetivos e objetos da pesquisa etc.). (1994, p. 99)

A instituição escolar, sanciona e expressa a ordem dominante com suas estratégias. É o campo minado, que hoje sistematiza e impõe o ensino remoto emergencial. Não obstante, os sujeitos que nela estão agem dentro desse campo de forma rápida e criativa, agem entre as brechas e fissuras do sistema. Ainda de acordo com o autor:

(...) chamo de tática a ação calculada que é determinada pela ausência de um lugar próprio. Então nenhuma delimitação de fora lhe fornece a condição de autonomia. A tática não tem lugar senão o do outro. E por isso deve jogar com o terreno que lhe é imposto tal como o organiza uma lei de uma força estranha. Não tem meio para si manter em si mesma, à distância, numa posição recuada, de previsão e de convocação própria: a tática é movimento "dentro do campo de visão do inimigo", como dizia Von Büllow, e no espaço por ele controlado. (CERTEAU, 1994, p. 100)

Nesse contexto, de crise humanitária instalada, em que possibilitar o acesso a educação para todos é um grande desafio em meio às discrepâncias de acesso aos bens mais fundamentais de sobrevivência, afirmamos a construção de um saber-fazer docente "corazonado" que cria e resiste a partir de "táticas de sobrevivência e astúcias de praticantes" nesse campo minado da escola, do ensino remoto emergencial e da internet.

\section{Entrelaçando os fios}

As professoras que escrevem este artigo o fazem a partir das suas experiências com e na educação infantil. Narramos experiências que consideramos exitosas de uma práxis em diálogo com o Ensino das Relações Étnico-raciais (BRASIL, 2003, 2004; GOMES, 2012; PEREIRA, 2018), com as Diretrizes Curriculares Nacionais para a Educação Infantil (BRASIL, 2010), a Cibercultura (SANTOS, 2019), as Tecnologias Sociais (COSTA e JESUS, 2013) e epistemologias geradas a partir do Sul (SANTOS, 2019).

Os referenciais acima formam redes reflexivas sobre possibilidades de pensar e fazer uma educação antirracista nesse tempo de pandemia, de ensino remoto emergencial, de precarização do trabalho docente e do radical cerceamento da infância, enquanto categoria social dotada de direitos (SARMENTO e PINTO, 1997).

Para o Patrono da educação brasileira não existe construção de consciência crítica fora da práxis, ou seja, fora da ação-reflexão-ação. Pois, nesse caminho dialético os seres humanos transformam a si e o seu mundo. Nesse diapasão duas premissas fundamentais nos servem de alicerces: professores são sujeitos criativos, atores de suas práticas e construtores de conhecimentos artesanais próprios, mobilizados em lutas concretas (SANTOS, 2019, p. 196); 


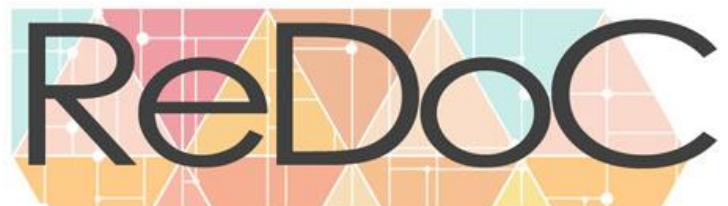

\section{Revista Docência e Cibercultura}

os caminhos metodológicos atravessados pelas mídias sociais e artefatos tecnológicos não buscam apenas acessar o estudante, mas produzir conhecimentos para o fortalecer as diferenças nos processos de luta desde o Sul (SANTOS, 2019).

Boaventura de Sousa Santos, na obra A Cruel Pedagogia do Vírus (2020), editada logo após a declaração da pandemia pela Organização Mundial da Saúde, afirma que qualquer quarentena é sempre discriminatória, e atravessá-la é mais difícil para certos grupos sociais. Para ele, mulheres, trabalhadores informais, populações na rua e moradores de periferias, têm sua situação de vulnerabilidade bastante agravada pela pandemia. Os sujeitos que estão no Sul representam um "espaço-tempo político, social e cultural" (p. 15) específico. E os professores e estudantes falam desse lugar epistemológico.

Em suas comunidades, docentes são confrontados com crianças e jovens em fragilidade extrema, que só tinham a escola para suprir sua alimentação diária, e aos quais hoje falta o básico: um prato de comida digno. Para muitas dessas crianças, jovens, adultos e idosos periféricos, seu maior espetáculo hoje é comer, parafraseando a escritora negra e favelada Carolina Maria de Jesus. Para muitas de nossas crianças, o quarto de despejo é um lugar íntimo, onde suas infâncias são ceifadas por abusos, exploração, negligência e ausências de todo tipo, que só vem crescendo ao longo da pandemia. Entre elas, a de encantamentos para tornar seu presente um pouco mais leve e sonhar um futuro digno de ser vivido. Poderíamos continuar fazendo inúmeras referências. Mas não é esse o nosso foco.

Queremos retomar a denúncia de que a desigualdade social e a digital estão imbricadas na sociedade brasileira e que os educadores se veem frente a limites muito concretos que, em certo sentido, os emparedam. A precariedade do sinal da internet se agudiza à medida em que adentramos nas periferias, segundo dados ${ }^{8}$ e pesquisas recentes (KNOP, 2020), o acesso à Rede exclusivamente por meio de aparelhos de celular é de $85 \%$ entre as populações de baixa renda, $47 \%$ dos lares rurais não possuem qualquer acesso à internet.

Edméa Santos nos alerta, nunca é demasiado reiterar, que não é suficiente a habilidade no uso do computador, dos softwares, do site, do portal, da consulta online, do e-mail, do upload e do download para que possamos considerar um indivíduo efetivamente capaz de ultrapassar a dimensão física do seu pensar ou agir ${ }^{9}$. É fundamental que ele ou ela possa intervir, como autor,

\footnotetext{
${ }^{8}$ Para dados atualizados sobre a desigualdade digital, a leitura do artigo de Gilnei J.O. da Silva, A desigualdade digital conectada à Pandemia é uma boa porta de entrada.

${ }^{9}$ A caracterização da autora é, mais especificamente, a de que a inclusão deve permitir ao usuário o deslocamento cultural do mundo analógico - o real, compreensível e palpável fisicamente - para o universo definido essencialmente como plasticidade combinatória de 0 e 1 .
} 


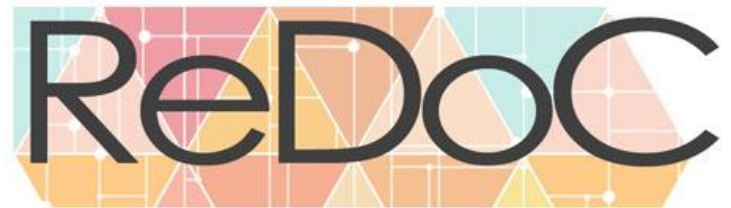

\section{Revista Docência e Cibercultura}

no ciberespaço. Isto é, que produza, interaja, desencadeie dinâmicas de produção nas mais diversas linguagens (SANTOS, 2019, p. 44/5).

Imersos na desigualdade, mas sem se render a ela, professores, esses atores sociais oriundos do Sul, têm produzido ao longo de sua prática profissional conhecimentos artesanais e científicos, que o fazem assumir uma responsabilidade subjetiva, levando-os a compreender e a transformar o mundo.

\section{Tempo de perguntas fortes}

Segundo Boaventura de Souza Santos (2018), vivemos em um tempo de perguntas fortes e de respostas fracas. Se ontem as respostas se apresentavam frágeis, hoje, elas parecem estar por um fio. E a escola, diante do paradoxo da desigualdade social que gera desigualdade digital, se configura um sistema em desequilíbrio, no qual o professor é aquele que se mantém na ponta da rede, mesmo com todos os fios fragilizados.

A metáfora da rede (DOMINICK et al., 2017, p. 185) diz que nós, docentes, fazemos parte de uma teia em que tramamos, nos enlaçamos, seguramos uma ponta e, a cada movimento dos muitos que estão a ela conectados, temos que nos transformar e reorganizar nossos corpos, sentimentos e certezas, pois o outro (lê-se aqui o sistema em desequilíbrio) é aquele que nos desequilibra. Em síntese, se não encararmos esse desafio com criatividade, táticas, solidariedade e vontade política, corremos o risco de contaminar/paralisar os corpos (os nossos, de nossos pares e dos nossos discentes) em seus modos de sentir, agir e pensar. Corremos o risco de romper com a rede.

Mas ainda há tempo de buscar resposta fortes, de firmar o nosso lugar de resistência - nosso lugar à Sul- e da luta por uma vida honesta, que reconhece a alegria como potência e nos leva à lugares onde a tristeza nunca levaria, como já o disse o poeta. Ainda há tempo de corazonar, de lembrar Paulo Freire em sua potente afirmação: ensinar exige a convicção de que a mudança é possível (1996).

\section{CAMINHOS METODOLÓGICOS}

As epistemologias do Sul referem-se à produção e à validação de conhecimentos ancorados nas experiências de resistência de todos os grupos sociais que têm sido sistematicamente vítimas de injustiça, da opressão e da destruição causadas pelo capitalismo, pelo colonialismo e pelo patriarcado. Chamo o vasto e muito diverso âmbito dessas experiências de Sul anti-imperial. Trata-se de um Sul epistemológico, 
não geográfico, composto por muitos suis epistemológicos que têm em comum o fato de serem conhecimentos nascidos em lutas contra o capitalismo, o colonialismo e o patriarcado. (SANTOS, 2019, p. 17)

As professoras que apresentam aqui suas reflexões e práticas, compartilham um pertencimento territorial - Magé, cidade periférica do Rio de Janeiro ${ }^{10}$. Território que carrega a marca da resistência de homens e mulheres escravizados e de seus descendentes, que ao longo dos séculos resistem a diferentes tipos de opressões e exclusões. Um dos nossos exemplos de resistência pedagógica transforma parte dessa história em astúcias/táticas docente praticadas em uma escola ${ }^{11}$ situada no bairro do primeiro território de remanescente quilombola da Baixada Fluminense do Rio de Janeiro, o quilombo de Maria Conga.

Somos professoras, formadoras e pesquisadoras em escolas que recebem crianças de classes populares e viemos também desses espaços que estruturalmente foram/são marcados por lógicas opressoras, hierarquizadas e racistas. A proletarização da docência nos coloca em um lugar que é partilhado com os grupos sociais vítimas de injustiças, opressões e exclusões.

Nesse período de pandemia as inúmeras barreiras que enfrentamos cotidianamente se acentuaram com a emergência do ensino remoto. Mais uma vez, como em um campo minado, lançamos mão do equilíbrio tático, dos conhecimentos artesanais e científicos produzidos em lutas anteriores (SANTOS, 2019) para garantir a construção de uma educação crítica e reflexiva a partir do Sul epistemológico.

Em O fim do Império Cognitivo, Santos (2019), dedica extensa parte de suas análises às metodologias pós-abissais. Ao abordar a descolonização das metodologias o autor afirma que "a natureza colonialista das metodologias desenvolvidas pelas ciências modernas abissais reside no fato de todas elas serem concebidas com base na lógica do extrativismo" (p. 193) ${ }^{12}$. Ainda segundo o intelectual português, a descolonização das metodologias ocorre quando todos os processos produzem conhecimentos aceitáveis e confiáveis de modo não-extrativista, ou seja, através da ajuda mútua entre os sujeitos e "não por meio de interações unilaterais sujeito/objeto" (p. 194) ${ }^{13}$. A experiência da professora - também autora do texto - nos revela caminhos metodológicos que dialogam com conhecimentos nascidos em lutas pessoais e coletivas, para além dos conhecimentos científicos e construídos em redes colaborativas. A seguir, narrativas do que vamos chamar de conhecimentos para serem usados na luta:

\footnotetext{
${ }^{10}$ A exceção da professora Marcia Guerra, cujos caminhos se entrelaçam aos nossos pela docência não escolar.

${ }^{11}$ Escola municipal Magide Repani, localizada no bairro do Saco ( $1^{\circ}$ distrito de Magé), onde está situado o território quilombola de Maria Conga.

${ }^{12}$ Ver mais sobre essa categoria em Santos (2019, p. 194).

${ }^{13}$ Essa é o que Boaventura chama de metodologia antiextrativista e pós-extrativista.
} 
Situações vivenciadas no cotidiano da Educação Infantil me impulsionaram a pesquisas sobre as relações étnico-raciais em busca de uma prática Pedagógica antirracista. Minha prática Pedagógica tem se pautado nas Microações afirmativas (...), na promoção e protagonismo da criança negra em sala de aula, seja através da literatura, desenhos animados, cartazes ou brincadeiras. No início do ano corrente, o planejamento foi pensado a partir das práticas que me trouxeram um "feedback" do ano anterior e o acréscimo de novas propostas. No entanto, ao sermos surpreendidos com a pandemia da Covid-19, muitas perguntas vieram: como pensar a promoção das relações étnico-raciais no cotidiano da Educação Infantil? Como adaptar as atividades propostas de forma a que alcancem o meu aluno? Haja vista que sabemos da disparidade socioeconômica do nosso país e a falta de acesso à tecnologia por grande parte da população, assim como nossos alunos.

(Narrativa docente - Conhecimentos para serem usados na luta)

A narrativa da professora é claramente a de alguém que faz da sua vida um pensar militante, onde teoria e prática andam juntas. Para Oliveira (2018, p. 66), ser militante significa ter uma postura de vida comprometida a uma causa. Militante ou engajado, é aquele que se filia à uma linha ideológica, filosófica e que se coloca a serviço de uma ideia. A ideia forte defendida aqui é a da educação antirracista para instituir novas formas de estar/pensar o mundo a partir de nós mesmos. Ideias fortes, inspiram respostas fortes:

[...] era necessário promover uma prática pedagógica que fosse prazerosa, que atendesse minimamente os objetivos propostos para Educação Infantil e que não estressasse ou criasse ansiedade nas crianças na forte exposição tecnológica que vinham sofrendo nesse período. Como todos os professores, em meio a vários questionamentos, passei a pesquisar sobre produção de vídeos, edições, avatares, a fim de adaptar minha prática a nova realidade. Vale ressaltar a rede de solidariedade que se formou onde vários professores produziram vídeos instrucionais (tutorial) para auxiliar outros professores em suas práticas. Diante deste cenário, passei a criar vídeos com pequenas histórias onde promovia a representatividade do negro perpassando as questões de identidade e autoestima. Escolhi as mídias sociais para divulgar as atividades devido o seu alcance às classes populares, mesmo ciente de que algumas crianças não seriam alcançadas por diversos fatores e não somente a falta de acesso tecnológico.

(Narrativa docente - Conhecimentos nascidos na luta ${ }^{14}$ )

A segunda narrativa que trata dos conhecimentos nascidos na luta, aponta para apropriação de métodos e técnicas digitais para a construção de processos educativos mais conectados com a

${ }^{14}$ Importante frisar que entre os conhecimentos para serem usados na luta e os conhecimentos nascidos na luta, há distinções, segundo Santos (2018). "Conhecimentos nascidos na luta são o reflexo da ação/ reflexo-com-reflexão que torna possível uma visão complexa do presente histórico. Já os conhecimentos para serem usados na luta representam aqueles produzidos em outras lutas, em outros tempos e lugares, mas que são úteis à dada luta. Para o autor, essa distinção pode tornar-se problemática em virtude da dificuldade de definição" (p. 196). 


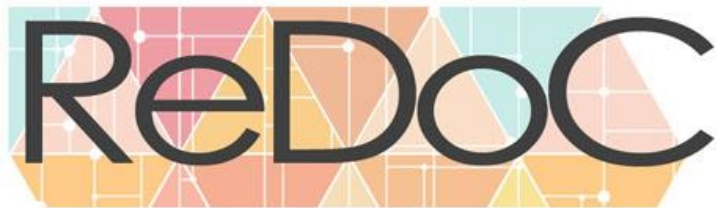

\section{Revista Docência e Cibercultura}

vida, nas suas diferenças culturais e étnicas. É visível a interlocução das narrativas com os princípios e fundamentos norteadores das Diretrizes Curriculares Nacionais da Educação Infantil (BRASIL, 2010), em que seus princípios tratam da ética, da política e da estética.

Combinam-se, na performance da professora, a efetiva autoria digital proposta por Edméa Santos e a apropriação metodológica das Tecnologias Sociais (COSTA e JESUS, 2013), como alternativa de tornar potente o processo educativo. Como já frisamos, segundo a professora da UERJ, tornar-se autor e permitir que seus interlocutores e alunos também o façam é empoderar sujeitos no ambiente não analógico. Exige o mobilizar complexo do conhecimento e a participação dos atores da comunicação e da aprendizagem em redes que conectam conteúdos, pessoas e lugares físicos e online (SANTOS, 2019). Retomando Costa e Jesus (2013), a lógica que orienta uma tecnologia social é a de que cidadãos, asssociações de bairro, organizações não-governamentais, movimentos sociais e outras instituições da sociedade civil organizadas podem desenvolver, apropriar-se de, ou adequar tecnologias em benefício de sua coletividade. Assim:

O termo "tecnologia social" é pensado de forma ampla para as diferentes camadas da sociedade. O adjetivo "social" não tem a pretensão de afirmar somente a necessidade de tecnologia para os pobres ou países subdesenvolvidos. Também faz a crítica ao modelo convencional de desenvolvimento tecnológico e propõe uma lógica mais sustentável e solidária de tecnologia para toda as camadas da sociedade. Tecnologia social implica participação, empoderamento e autogestão de seus usuários (...) (COSTA e JESUS, p. 19, 2013).

Ao defendermos uma educação enquanto práxis, fazemos uma escolha política de pensar o mundo de maneira crítica e reflexiva. Em outras palavras, teoria e prática devem estar juntos, caminhos de formação pessoal, profissional e acadêmica devem se conectar para tornar a rede mais resistente. Ao trazer para a cena a categoria de imaginação epistemológica, Boaventura nos aponta "a necessidade de imaginar as consequências da não separação da vida e investigação” (p. 191, 2019). Quando não há essa cisão, o investigador pós-abissal se transforma em um artesão que se apropria das ferramentas metodológicas de forma criativa, capaz de construir o seu método (SANTOS, 2007). É sobre esse potencial criativo e autoral que falaremos a seguir.

\section{RESULTADOS}

Conhecimentos artesanais: porque nós somos feitos de histórias

E descobri perguntando. Perguntando e me perguntando de onde vinha este planeta que habitamos, que a cada minuto gasta um milhão de dólares em armamentos para que a cada minuto trinta crianças morram impunemente de doenças ou fome. 
Perguntando e me perguntando: este nosso mundo, este matadouro, este manicômio, é obra de Deus ou dos homens? Que tempo passado pariu este tempo presente? Por que uns países fizeram-se donos de outros países, e uns homens donos de outros homens, e os homens donos das mulheres, e as mulheres das crianças, e as coisas donas das pessoas?

(Galeano, $\left.1993^{15}\right)$

Perguntas fortes continuam ecoando, para além da história e espaços-tempos distintos. Nós, professores, insistimos em respondê-las com a esperança que, similar a utopia evocada pelo pensador uruguaio, nos impele a caminhar rumo ao horizonte. E a alegria do caminho é conhecer novas histórias, novos sujeitos que em seu cotidiano sabem que seu saber é poder, e por isso, correm riscos, cuidam das feridas e seguem.

Nas próximas páginas, partilharemos descrições de audiovisuais ${ }^{16}$ nascidos da descolonização metodológica que objetivou fortalecer a luta antirracista, as respostas que se faziam fracas e sua identidade criativa - imbuídas de táticas e astúcias. São materiais que estão disponíveis em plataformas de compartilhamentos como YouTube e redes sociais (facebook e instagram) para livre acesso.

Reconhecendo a importância do acesso e apropriação aos dispositivos legais que regem a Educação Infantil, destacaremos os princípios indicados pelas Diretrizes Curriculares Nacionais para a Educação Infantil como fundamentos norteadores da primeira etapa da Educação Básica, a saber: princípios éticos, princípios políticos e princípios estéticos (DCNEI, 1996).

\section{Conhecimentos artesanais: Princípios Éticos}

Princípios Éticos: da autonomia, da responsabilidade, da solidariedade e do respeito ao bem comum, ao meio ambiente e às diferentes culturas, identidades e singularidades (BRASIL, 2010).

\footnotetext{
${ }^{15}$ Ver obra: SER COMO ELES - $1^{\mathrm{a} E D}$. (1993)

${ }^{16}$ Tratam-se de produtos digitais (vídeos curtos) produzidos com aplicativos que permitem criar avatares (Zepeto, Avatoon, Bitimoji), editores gráficos para a criação de layouts, como o Canva. E software, como KineMaster para a produção dos vídeos. Todos de dominío público e ao alcance de todos com tradução em português.
} 


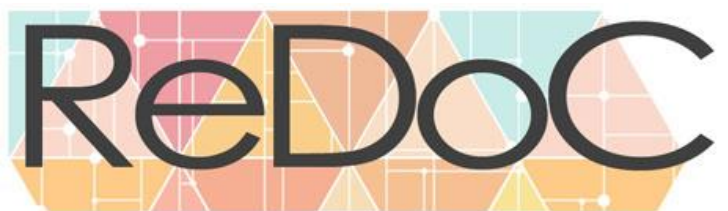

\section{Revista Docência e Cibercultura}

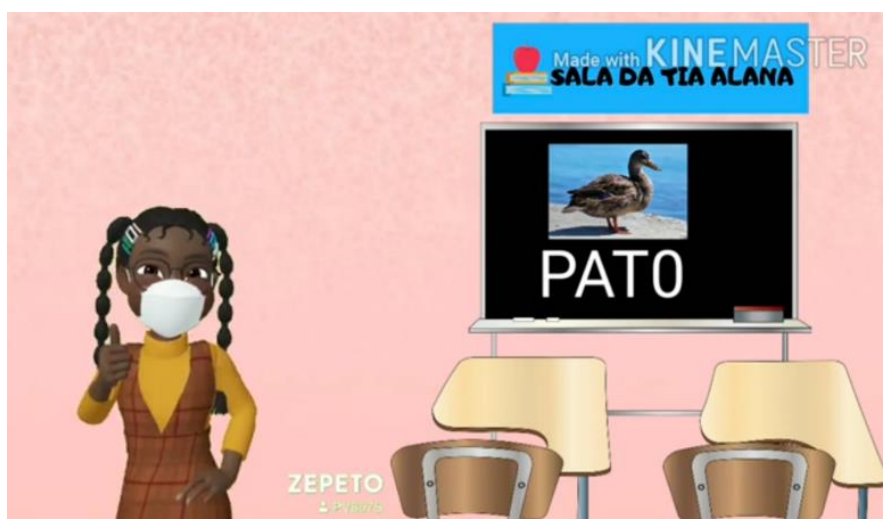

Figura 1: Vídeo com avatares falantes - Leca _ Na sala da tia A.

Fonte: as autoras

O vídeo ${ }^{17}$ animado de 1 minuto e 46 segundos chamado: "Leca: Na sala da tia A.", tem por tema central o respeito e a responsabilidade coletiva com o bem comum. No comportamento de Leca, uma menina negra em situação protagônica, questões tais como representatividade, identidade, singularidade física e fenotípica são sublinhadas. E coadunam-se as Diretrizes Curriculares Nacionais para a Educação das Relações Étnico-raciais que defendem a ruptura de histórias que marginalizam (exemplo: pessoas escravizadas acorrentadas) e orientam para o uso de imagens que positivem a pessoa negra.

Leca explica aos que a ouvem que a escola está cumprindo os protocolos de isolamento social, por isso a sala está vazia. Sua voz é legítima, soa quase como oficial. Através dela o espectador o percebe que crianças são sujeitos de direitos que devem ser respeitados em suas necessidades, inclusive quando ouve música e brinca com o corpo. Musicalidade, corporeidade e ludicidade são valores ancestrais que não devem ficar de fora do desenvolvimento integral da criança.

Assim, ao longo do vídeo, a personagem dialoga com o estudante, estimulando a dança, a brincadeira, mas também a responsabilidade com o aprender. Apresenta a letra $\mathrm{P}$ de pato, seguida de um jogo para a consolidação da aprendizagem. Leca, muito simpática, finaliza o vídeo indicando a necessidade de sermos solidários e termos respeito ao bem comum, além da importância do uso a máscara facial.

\footnotetext{
${ }^{17} \mathrm{O}$ vídeo está disponível em Youtube: 〈https://www.youtube.com/watch?v=ruhWLZvKtQc>
} 


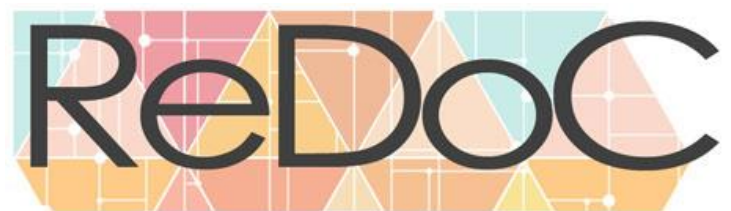

\section{Revista Docência e Cibercultura}

Conhecimentos artesanais: Princípios Políticos

Princípio Políticos: dos direitos de cidadania, do exercício da criticidade e do respeito à ordem democrática (BRASIL, 2010).

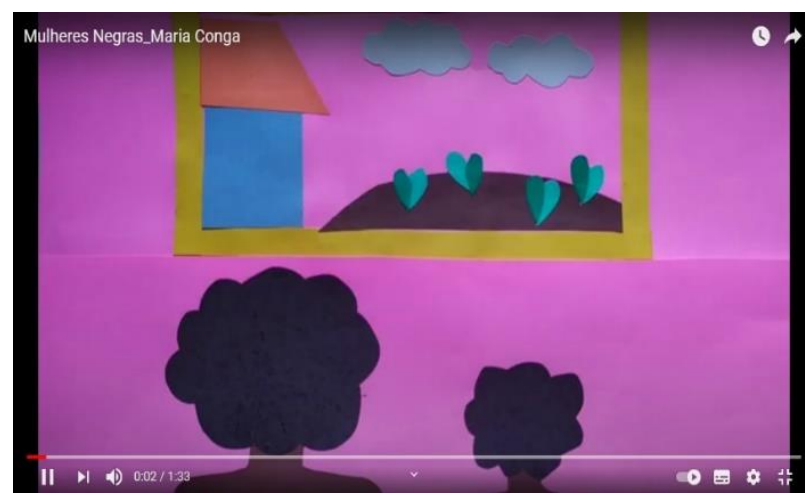

Figura 2: Vídeo Mulheres Negras_Maria Conga

Fonte: as autoras

No vídeo 18 "Mulheres Negras: Maria Conga", de 1 minuto e 34 segundos, mais uma vez nos confrontamos com a criatividade docente que por meio da pesquisa e do emprego de processos artísticos artesanais revela a relevância das experiências de vida dos grupos marginalizados, como os quilombolas. Proferidas do Sul epistêmico, as vozes da vovó griotê e da menina criança, comungam da resistência e da beleza do povo e das tradições do $1^{\circ}$ Território de Remanescente Quilombolas da Baixada Fluminense, o quilombo batizado pelo nome de mulher forte e guerreira: Maria Conga. A narrativa dialoga com outras produções realizadas no município de Magé e disponibilizadas na internet ${ }^{19}$, memórias ancestrais coletivas, bem como imagens-memórias de formação de vida pessoal, demonstram a busca docente pelo exercício da criticidade e pelos direitos de cidadania. A seguir, a descrição do enredo:

Vovó, conta a história daquele lugar onde meu avó tinha uma casinha, lá onde morava a Maria Conga? - Maria Conga foi uma mulher que nasceu no Congo, no Continente Africano em 1792. A Maria que veio do Congo chegou criança ao Brasil, em um navio negreiro. Foi vendida para o senhor de engenho de Salvador, sendo separada de sua família. Aos 18 anos, chegou em nossa cidade de Magé em 1810 pelo porto de Piedade. Aos 35 anos foi liberta e começou a ajudar os escravizados livres e fugidos das fazendas, começando sua trajetória como líder do quilombo. Maria Conga fez sua casa na mata, onde recebia os escravizados, formando o quilombo de Maria Conga. -

\footnotetext{
${ }^{18}$ Disponível em Youtube: < https://youtu.be/6OambZYmNpA >

${ }^{19}$ No canal Grupo Memória Resgate de Magé - Maria Conga - o único quilombo em Magé que viu a liberdade. Fonte: <https://youtu.be/KJtUHoxD014 > Canal ONG Estimativa - Maria Conga - Orgulho de ser quilombola. Herança quilombola: Maria Conga em Magé - Baixada Fluminense

< https://dmjracial.com/.../heranca-quilombola-maria-conga.../ > Todos acessados em 29/10/2020.
} 


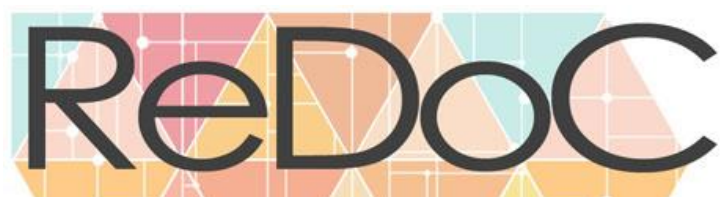

\section{Revista Docência e Cibercultura}

Vovó, Maria Conga foi uma verdadeira heroína! - Nós, mulheres negras, somos continuação dos passos de Maria Conga. Somos RESISTÊNCIA!

(Narrativa docente - História nascida na luta, pelas lutas anteriores ${ }^{20}$ )

Memória, ancestralidade e afetividade entremeadas com as táticas de quem entendeu que a luta se faz na comunhão de diferentes saberes e a indispensável leveza. As mulheres, protagonistas da animação elaborada com a técnica de recorte e colagem, falam também de um lugar de valor: o interior da família, compreendido como um lugar de diálogo, de escuta e de construção de saberes. Valorizando a comunidade, o pequeno artefato audiovisual nos mostra a responsabilidade comum da escola e da família no exercício da cidadania desde a tenra idade.

\section{Conhecimentos artesanais: Princípios Estéticos}

Estéticos: da sensibilidade, da criatividade, da ludicidade e da liberdade de expressão nas diferentes manifestações artísticas e culturais (BRASIL, 2010).

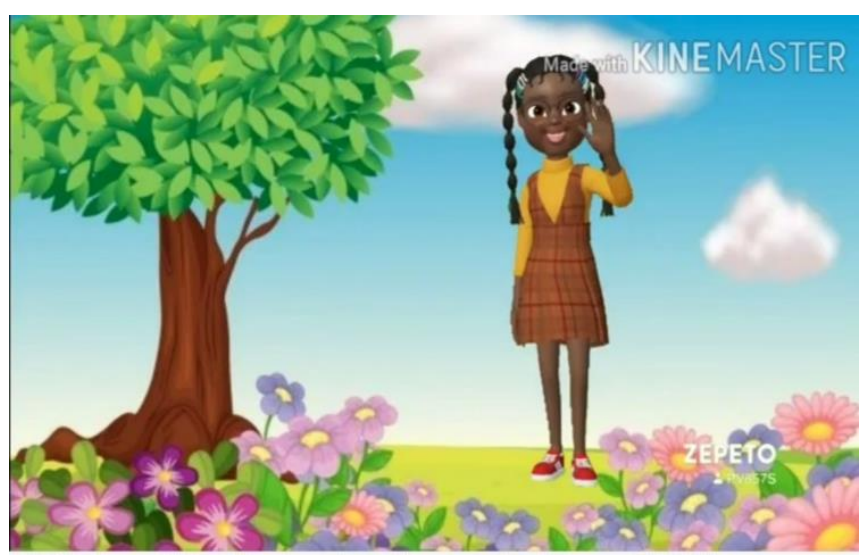

Figura 3: Avatar falante personalizado - Semana da Educação Infantil - Brincando em Casa Fonte: as autoras

\footnotetext{
${ }^{20}$ Narrativa autoral, baseada nas histórias contadas pelos quilombolas do Quilombo de Maria Conga. O vídeo participou do Projeto Infâncias Plurais do Itaú Cultural em 2020.
} 


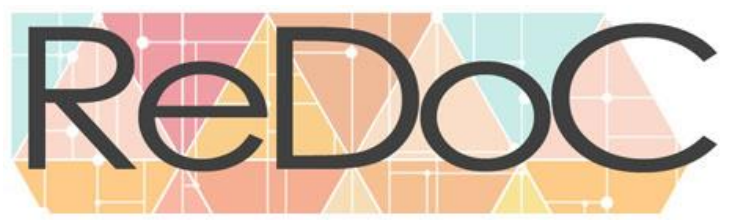

\section{Revista Docência e Cibercultura}

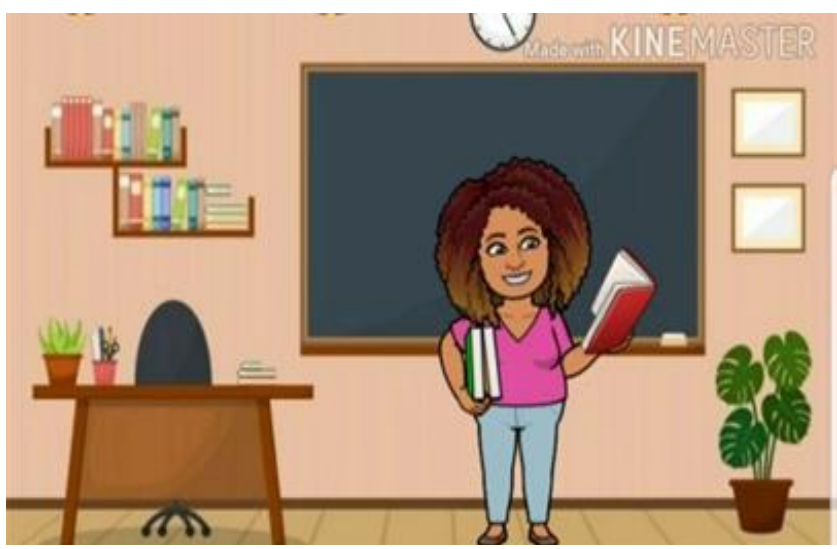

Figura 4: Avatar falante personalizado - Aula 7 de setembro

Fonte: as autoras

Nos vídeos ${ }^{21}$ animados 3 (tempo: 3:19) e 4 (tempo: 1:27), são demarcados os princípios estéticos, expressos pelas diversidades formas de ser e estar no mundo. Ao construir as personagens, a docente buscou uma técnica que possibilita a personalização dos avatares de acordo com as características relativas aos traços fenotípicos que predominam na comunidade escolar $^{22}$. O vídeo 3, dedicado à Semana da Educação Infantil, proporciona a criança experiências lúdicas, criativas e inovadoras com diferentes experimentos "mágicos", estimulando seu imaginário e propondo uma realidade alternativa. Já no vídeo 4, elaborado na semana de 7 de setembro, destacamos a diversidade de personagens, em sua maioria negros, que assumem a palavra e conversam de forma criativa com seus interlocutores. Em síntese, os vídeos têm forte impacto junto ao público ao qual se destinam. Através do protagonismo de personagens negras que expressam com sensibilidade, fantasia e criatividade diferentes manifestações artísticas, culturais e educativas do entorno das crianças, fomentam a autoestima e viabilizam o desenvolvimento saudável da criança.

\section{CONSIDERAÇÕES FINAIS}

\footnotetext{
Vou atravessar os mares Romper divisa e fronteira

Pois o começo da trama Deu-se em terra estrangeira
}

\footnotetext{
${ }^{21}$ Seguem os links: < https://www.youtube.com/watch?v=7AhGUzUEeo8>

< https://www.youtube.com/watch?v=x53xwvmugeU\&t=10s>

22 Aplicativos com a função de personalizar: Zepeto, Avatoon e Bitimoji.
} 


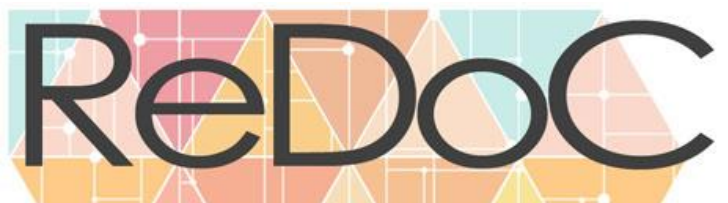

\title{
Revista Docência e Cibercultura
}

\author{
Numa nação africana \\ Bem longe da brasileira \\ É uma história verdadeira \\ Não duvide, tenha fé \\ Contando a trajetória \\ De uma importante mulher \\ Chamada Maria Conga \\ Heroína de Magé \\ (Gilmar Souza - Poeta Cordelista) $^{23}$
}

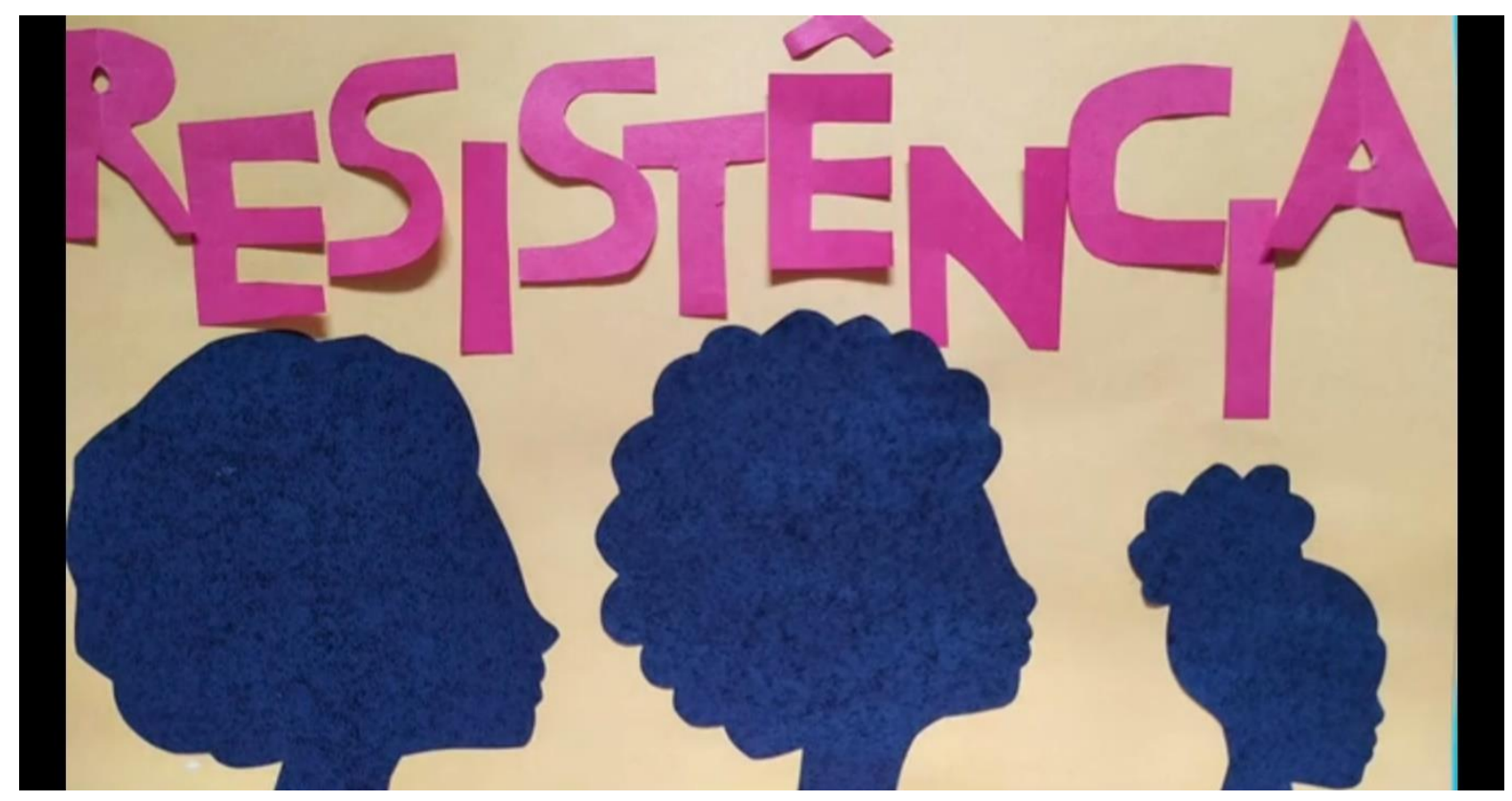

Figura 5: Vídeo animado Mulheres Negras_Maria Conga_Resistência

Fonte: as autoras

Uma educação que seja contrária à desigualdade, a opressão e à violência, é o nosso desejo e militância. Uma educação que questione o instituído: as políticas que matam e sufocam vidas negras a cada segundo em todo o mundo. Por uma educação que seja capaz de resgatar as infâncias que vêm sendo anuladas porque, vulneráveis às barbáries do mundo, seguem perdendo a oportunidade de presente e futuro dignos.

\footnotetext{
${ }^{23}$ Quilombola Guerreira é a poesia de cordel escrita pelo poeta Gilmar de Souza. Este cordel pode ser encontrado na íntegra no livro: A questão étnico-racial a partir do meu olhar sobre o olhar da criança: promovendo experiências instituintes. $1^{\mathrm{a}}$ ed. - RJ : Autografia, 2018. Autora: Daise dos S. Pereira.
} 


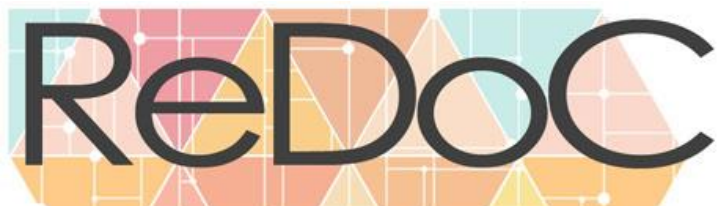

\section{Revista Docência e Cibercultura}

Por uma educação, em que os nossos pares se fortaleçam coletivamente dia após dia, apesar dos riscos, apesar das feridas, apesar de... E avivados por perceberem as injustiças compartilhem os riscos e as curas do processo. Professores táticos, premissa que nos alicerçou nesta escrita, são sujeitos criativos que fazem da sua prática profissional e também pessoal, um constante corazonar.

Nossas reflexões nos levaram a um resultado doloroso, mas já esperado: a arbitrariedade e a irresponsabilidade das distintas instâncias do governo nesse período de ensino remoto emergencial, somadas às negligências históricas, agravaram o combalido quadro da educação brasileira.

Parte importante dos nossos alunos vive em lares onde a doença chega com maior intensidade, assim como o desemprego e a fome. E são acompanhados pela pressão para que mais gente da família seja responsável por colocar comida na mesa. A precarização nos permite recordar o tempo em que a escola era considerada supérflua e os filhos dos explorados entregues a quem lhes pudesse alimentar: meninos aprendizes, aos cinco/seis anos de idade carregando baldes, compras, pedras; meninas criadas, empregadas no cuidado com e da casa, dos filhos ou satisfazendo as taras daqueles que por elas podem pagar. Imagens não tão distantes... Superadas pelo avanço na distribuição de renda e na escolarização.

A prolongada duração da pandemia do COVID-19, agravada pela ausência de políticas de proteção efetiva dos mais pobres dentre nós, encontra-se com a exclusão digital, que continua invisível para os poderes executivo, o legislativo e judiciário do país e promete tornar esse quadro ainda mais sombrio. Uma antecipação do desastre pode ser constatada na ausência de cerca de 50\% dos inscritos no Exame Nacional de Ensino Médio - ENEM. Quase 50\% de indivíduos que desistiram de um futuro atravessado pela educação superior. Faltou-lhes estímulos? Faltou-lhes um computador? Faltou o olhar acolhedor de um profissional da educação?

As narrativas docentes apresentadas ao longo do texto nos permitem constatar experiências exitosas. Muitas outras existem país a fora, todas sabemos. Sorte daqueles que podem usufruir dos conhecimentos e da determinação de educadores que compreendem o papel determinante da escola na superação das injustiças sociais.

Infelizmente, políticas públicas não podem ser urdidas tendo por base "habilidades individuais", "determinação individual" ou "consciências individuais". Por sua definição, precisam ser tecidas por governantes, agentes públicos e comunidade. Temos pela frente uma longa convivência com o vírus. Talvez ainda haja tempo, se houver vontade política, de 


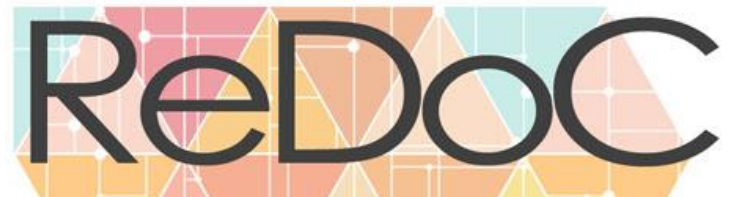

\section{Revista Docência e Cibercultura}

iniciarmos uma discussão efetiva sobre como garantir uma educação efetivamente libertadora em tempos tão sombrios. Até lá, esperamos nos multiplicarmos em Marias Congas.

\section{REFERÊNCIAS}

BRASIL. Parecer $\mathbf{C N E} / \mathbf{C P} \mathbf{n}^{\mathbf{0}} \mathbf{5 / 2 0 2 0}$, que define diretrizes para a reorganização dos calendários escolares e a realização de atividades pedagógicas não presenciais durante a pandemia de Covid-19. $\quad$ Disponível em $<$ http://portal.mec.gov.br/index.php?option=com_docman\&view=download\&alias $=14511$ pcp005-20\&category_slud=marco-2020-pdf\&Itemid=30192 > Acesso em 11/01/2021 .

BRASIL. Lei $\mathbf{n}^{\mathbf{0}}$ 10.639, de 9 de janeiro de 2003. Altera a Lei $\mathrm{n}^{\circ} 9.394$, de 20 de dezembro de 1996. Diário Oficial da União, Poder Executivo, Brasília, DF, 23 dez. 1996.

BRASIL. Ministério da Educação. Diretrizes curriculares nacionais e para a educação das relações étnico-raciais e para o ensino de história e cultura afro-brasileira e africana. Brasília, DF, 2004.

BRASIL. Ministério da Educação. Diretrizes curriculares nacionais para a educação infantil. Brasília, DF, 2010.

BRASIL. Ministério da Educação. Referencial curricular nacional para a educação infantil. Brasília, DF: MEC, 1998.

BITTENCOURT, M. Michel de Certeau 25 anos depois: atualidade de suas contribuições para um olhar sobre a criatividade dos consumidores. Revista Polêmica. v. 11, n. 2 (2012). Disponível em: https://www.e-publicacoes.uerj.br/index.php/polemica/issue/view/245. Acesso em: 20 de março de 2020.

CERTEAU, Michel de. A invenção do cotidiano: 1. Artes de fazer. Petrópolis: Vozes, 1994.

COSTA, A. B. e JESUS, V. M. B. Tecnologia Social: breve referencial teórico e experiências ilustrativas. In: COSTA, Adriano Borges. (Org.) Tecnologia Social e Políticas Públicas. São Paulo: Instituto Pólis; Brasilia: Fundação Banco do Brasil, 2013. (pp. 17-31)

DOMINICK, Rejany dos Santos et al (2017). Desafios à escola brasileira a aos seus profissionais: diversidade e inclusão. In: SANTIAGO, Mylene Cristina e AKKARI, Abdeljalil (orgs.) Formação de professores e perspectivas interculturais. $1^{\mathrm{a}}$ ed. - Rio de Janeiro : Autografia, 2017. 


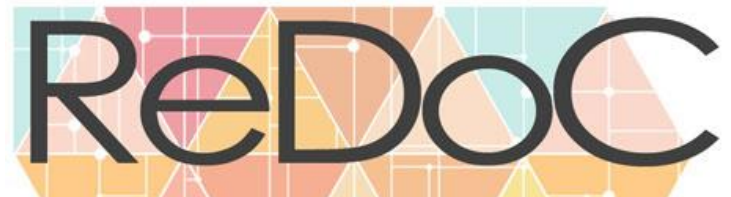

\section{Revista Docência e Cibercultura}

FLORES, N; ARNT, A. Desigualdade social e tecnologia: o ensino remoto serve para quem? COVID-19/ Blogs de Ciências da UNICAMP. São Paulo, 2020. Disponível em: < https://www.blogs.unicamp.br/covid-19/desigualdade-social-e-tecnologia-o-ensino-remotoserve-para-quem/> Acesso em: 18/01/2021.

FREIRE, Paulo. Pedagogia do Oprimido. Rio de Janeiro, Paz e Terra, 1987.

FREIRE, Paulo. Pedagogia da Autonomia. 33.ed. São Paulo: Paz e Terra; 1996.

GALEANO, Eduardo. As palavras andantes. Rio de Janeiro, L \& PM, 1993.

GOMES, Nilma Lino. O Movimento Negro educador, saberes construídos nas lutas por emancipação. Petrópolis: Vozes, 2017

KNOP, Marcelo Ferreira Trezza. Desigualdade Digital e Desigualdade Social no Brasil. Tese de Doutorado. UFJF- Juiz de Fora, 2020. Disponível em: < https://repositorio.ufjf.br/jspui/handle/ufjf/11695 > Acesso em: 20/01/2021.

OLIVEIRA, Luiz Fernandes de. Educação e Militância Decolonial. $1^{\text {a }}$ ed. - RJ: Editora Selo Novo, 2018.

PEREIRA, Daise dos Santos. A Questão Étnico-racial a partir do meu olhar sobre o olhar da criança: promovendo experiências instituintes. Rio de Janeiro: Editora Autografia, 2018.

PEREIRA, Daise dos Santos. A Questão Étnico-racial, perspectivas teóricas críticas e processos educativos em diálogo. Revista Novamerica. $\mathrm{N}^{\mathrm{o}} 165 *$ jan-mar/2020. Disponível em: http://www.novamerica.org.br/ong/?p=1503. Acessado em 14/04/2020.

PEREIRA, Márcia Guerra; PEREIRA, Daise dos Santos. A (re)significação das imagensmemórias da formação docente para a inclusão da diversidade. XVIII ENDIPE, UFMT. Cuiabá, 2016. Disponível em: < https://www.ufmt.br/endipe2016/artigos-completos-eixo-2/> Acesso em: 10/01/2021.

SANTOS, Boaventura de Sousa. O fim do Império Cognitivo: a Afirmação das Epistemologias do sul - $1^{\text {a }}$ Ed. Belo Horizonte: Autêntica Editora, 2019.

SANTOS, Boaventura de Sousa. Para além do pensamento abissal: das linhas globais a uma ecologia de saberes. Novos estudos. - CEBRAP [online]. 2007, n.79, pp.71-94. Disponível em: $<$ http://www.scielo.br/scielo.php?script=sci_arttext\&pid=S0101-

33002007000300004\&lng=en\&nrm=iso>. Acessado em: 21-01-2021.

SANTOS, Boaventura de Sousa. A Cruel Pedagogia do Vírus. Coimbra: Ed. Almedina, 2020.

SANTOS, Boaventura de Sousa. Os Conceitos que nos faltam. Outras Palavras: Instituto Humanitas Unisinos, 2018. Disponível em: <http://www.ihu.unisinos.br/78-noticias/581624boaventura-os-conceitos-que-nos-faltam> Acesso em: 20/01/2021.

SANTOS, Edméa. Pesquisa - Formação na cibercultura. Teresina: EDUFPI, 2019. 


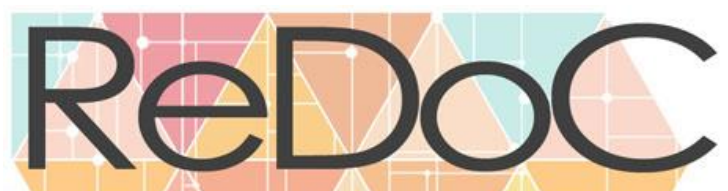

Revista Docência e Cibercultura

SARMENTO, Manuel Jacinto; PINTO, Manuel. As crianças e a infância: definindo conceitos, delimitando o campo. In: PINTO, M.; SARMENTO, M. As crianças, contextos e identidades. Braga: Centro de Estudos da Criança, 1997.

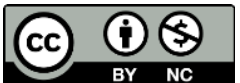

Este é um artigo de acesso aberto distribuído sob os termos da Licença Creative Commons Atribuição Não Comercial-Compartilha Igual (CC BY-NC- 4.0), que permite uso, distribuição e reprodução para fins não comerciais, com a citação dos autores e da fonte original e sob a mesma licença. 